\title{
BMJ Open Ecological study of the association between mental illness with human development, income inequalities and unemployment across OECD countries
}

\author{
Guillaume Barbalat (D), Nicolas Franck
}

To cite: Barbalat G, Franck N. Ecological study of the association between mental illness with human development, income inequalities and unemployment across OECD countries. BMJ Open 2020;10:e035055. doi:10.1136/ bmjopen-2019-035055

- Prepublication history and additional material for this paper are available online. To view these files, please visit the journal online (http://dx.doi. org/10.1136/bmjopen-2019035055).

Received 17 0ctober 2019 Accepted 31 March 2020

D Check for updates

(c) Author(s) (or their employer(s)) 2020. Re-use permitted under CC BY-NC. No commercial re-use. See rights and permissions. Published by BMJ.

Centre Hospitalier le Vinatier \& UMR 5229, CNRS \& Université Lyon 1, Lyon, France

Correspondence to Dr Guillaume Barbalat; guillaumebarbalat@gmail.com

\section{ABSTRACT}

Objectives Recent studies have demonstrated worsened mental health in relatively highly developed countries impacted by social inequalities and unemployment. Here, we investigate (1) whether mental health issues are differently or similarly affected by these social factors and (2) whether their effects on mental health are related or unrelated to each other.

Setting Analysis at the country level among Organization for Economic Cooperation and Development (OECD) countries $(n=36)$. Data on social indicators were collected from OECD and the United Nations Development Programme databases. Data on the prevalence of mental issues were obtained from the Institute for Health Metrics and Evaluation's Global Burden of Disease study 2017.

Participants No involvement of participants.

Primary and secondary outcome measures Using linear regression models, we investigated the relative contribution played by human development (as measured by the Human Development Index (HDI)), social inequalities (Gini index) and unemployment (unemployment rate) on the prevalence of 10 mental health issues. We then measured the relationship between the socioeconomic factors' effects on mental issues using $2 \times 2$ Pearson's correlation test and principal component analysis.

Results First, the overall effect of each socioeconomic factor on a combination of mental health disorders was large ( $r$ range: 0.51 to $0.76 ; p<0.002$ ). However, the influence of social factors on mental health was relative to each mental issue ( $r$ range: -0.34 to 0.74 ). Second, the socioeconomic factors' effects on mental health showed strong interdependence $\left(r_{\text {HDI-Gini }}=0.93, r_{\text {HDI-unemploy }}=0.81\right.$, $r_{\text {unemploy-Gini }}=0.84 ; p<0.001$. Principal component analysis demonstrated that the first principal component of the three variables $\left(r_{H D}, r_{\text {Gini }}, r_{\text {unemploy }}\right)$ explained $91.5 \%$ of the variance.

Conclusion These results implore a reanalysis of the socioeconomic determinants of mental health where (1) the heterogeneity of mental health issues would be taken into account and (2) each socioeconomic indicator's effect would be analysed and interpreted in conjunction with the others.

\section{INTRODUCTION}

A significant proportion of the overall disease burden is related to mental disorders. For

\section{Strengths and limitations of this study}

- To allow for comparability across populations and minimise the risk of outliers, our study focused on Organization for Economic Cooperation and Development countries, which are mostly highincome countries.

- Data on the prevalence of 10 mental issues were obtained from the Institute for Health Metrics and Evaluation's Global Burden of Disease study 2017, from which an increasing number of high-impact epidemiological studies has already been published.

- Our analysis took into account overall healthcare spending and potential outlier countries.

- The ecological design was necessary because our research questions were directly related to the association of national-level mental health prevalence and socioeconomic indicators; however, there is no possibility to make inferences about individuals from this dataset.

- The observational nature of our analysis means that other uncontrolled sociocultural factors might have influenced the prevalence of mental issues in individual countries.

instance, depressive disorders and schizophrenia account for as much as 63200 and 15000 absolute disability-adjusted life year per thousand people, which makes them the second and the eleventh most burdensome disorders, respectively. ${ }^{1}$ Suicide is also a serious global public health issue, being among the top 20 leading causes of death worldwide and the second leading cause of death in young people aged 15-29 years. ${ }^{2}$ Therefore, how to promote mental health at a wide, public health level is a crucial matter.

Following the biopsychosocial account of mental disorders, one can say that mental health is currently promoted at three basic levels. First, the increasing knowledge of biological determinisms of mental illness has led to great efforts (but not necessarily successes) to destigmatise patients with a 
mental disorder that is beyond their control. ${ }^{3}$ Second, psychological attributes such as confidence, agency, optimism or resilience are now widely used to promote mental health at a public health level. ${ }^{4}$ Third, important insights have revealed that discrimination based on sociodemographic factors such as socioeconomic status, race, ethnicity, gender and sexual orientation can have a huge impact on mental health. ${ }^{5}$

However, contrary to biological and psychological factors that are now routinely addressed by clinicians, practitioners keep struggling to meet their patients social needs. Recent accounts emphasise the need for a better awareness of the social, economical and political determinants of mental health among mental health practitioners. ${ }^{6}$ Those accounts call for a better recognition of how structures (such as institutions, systems or policies) bias social justice against certain types of people and shape symptoms and diseases-especially mental disorders. Recognising factors that participate to structural discrimination in day-to-day practice would be crucial to advocate for the reduction of inequalities both in clinical interactions and, perhaps even more importantly, to promote better mental health at a public health level. ${ }^{7}$

In the current study, we chose to leave aside dimensions of structural discrimination related to race, gender, religion and sexual orientation to focus on country-level socioeconomic status and its relationship to mental health disorders prevalence. We investigated three measures meant to define the social and economic status of a nation: human development, income inequalities and unemployment rate. Human development, which is composed by a measure of health, education and standard of living, aims at representing the average level of freedoms, opportunities and financial wealth of a country. Income inequalities gives insight on how wealth is distributed within a nation. Finally, unemployment rate measures the percentage of people without a professional occupation.

Recent studies have suggested that relatively highly developed countries demonstrate worsened mental health when impacted by income inequalities ${ }^{8-10}$ and unemployment. ${ }^{11}$ Although this has been of great interest to social epidemiologists, two important questions have remained unanswered. First, it is unclear whether mental health issues are differently or similarly affected by these social factors. International classifications such as the Diagnostic and Statistical Manual of Mental Disorders or the International Classification of Diseases define mental disorders as a constellation of potential problems rather than a single, unifying issue. ${ }^{12}{ }^{13}$ The question is therefore whether socioeconomic indicators influence those various disorders in a different or similar manner. Given the heterogeneity of mental health problems, one would expect a differential impact of these social factors on various mental health issues, where for instance, bipolar disorders would have a different relation to socioeconomic indicators than schizophrenia or alcohol use disorders. On the other hand, recent accounts of mental issues have criticised the view that mental disorders were discriminable. Those accounts are based on clinical, biochemicals, genetics and cognitive neuroscience studies that have suggested fairly similar mechanisms underpinning different mental diseases such as schizophrenia, depression, anxiety disorders and attention-deficit and hyperactivity disorders (ADHD).$^{14}$ Following this account, one would expect that social factors would influence different mental disorders in a rather similar way.

A second uncertainty is whether those socioeconomic factors' effects on mental health are related or unrelated to each other. On the one hand, there are theoretical reasons to believe that those socioeconomic factors may have a correlated impact on mental problems. A common path to mental well-being may be that of income, wealth and perhaps success, where development would relate to average wealth, inequalities to wealth distribution and unemployment to the main source of wealth for most people. On the other hand however, development, inequalities and unemployment usually vary in a way that is grossly uncorrelated..$^{15}$ Thus, according to this account, there is no a priori empirical reason to suspect that their effects on mental health are related to each other.

This study aimed at better categorising the relations between development, inequalities and unemployment with the prevalence of various mental health issues at the country level. To allow for comparability across populations and minimise the risk of outliers, we restricted our analyses to the 36 relatively rich countries that belong to the Organization for Economic Cooperation and Development (OECD). This choice is based on the fact that, in developing countries, mental disorders could rely on other social factors than the ones we investigated in the current study, such as human rights and inland security. ${ }^{16}$ Likewise, there seems to be key differences between developing and developed countries in how human development affects mental health. While the prevalence of mental disorders such as depression decreases when the level of human development increases, developed countries seem to demonstrate an opposite pattern: the higher their level of development, the higher their prevalence of mental disorders. ${ }^{17}$

We restricted our analysis to the most common mental health disorders, that is, depressive disorders, bipolar disorders, schizophrenia, eating disorders, anxiety disorders, ADHD, alcohol use disorders and autism spectrum disorders. As an obvious public mental health issue, we also added suicide prevalence to our analysis. Two caveats are related to the collection of prevalence data on mental disorders across countries. First, the range of epidemiological studies meant to report prevalence data are unequally distributed across issues, age groups and countries. ${ }^{18}$ To overcome this challenge, we chose to collect data on the prevalence of mental health disorders from the Institute of Health Metrics and Evaluation (IHME)'s Global Burden of Disease (GBD) study $2017 .{ }^{19}$ To the best of our knowledge, this is currently the only source which produces global level estimates across countries where diagnostic categories for mental health and alcohol use disorders are adequately represented. Second, prevalence data could reflect, at least in part, different healthcare spending across countries 
Table 1 Descriptive statistics for dependent and independent variables $(n=36)$

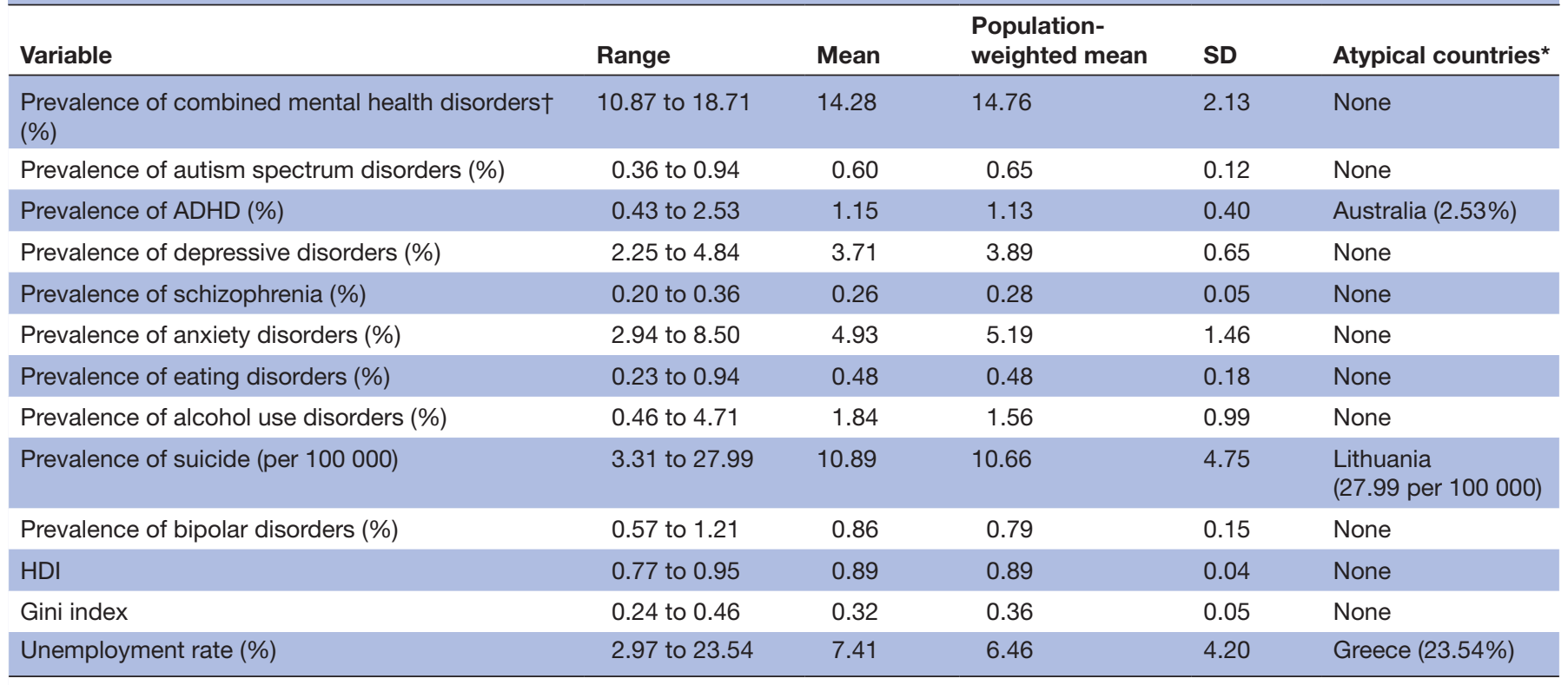

*Whose $z$-score is greater than 3 or below -3 .

†This includes autism spectrum disorders, ADHD, conduct disorders, idiopathic developmental intellectual disability, depressive disorders, schizophrenia, anxiety disorders, eating disorder and bipolar disorders.

ADHD, attention-deficit and hyperactivity disorder; HDI, Human Development Index.

rather than giving a representative perspective on specific differences between countries. Countries that spend a lot on healthcare would likely show inflated prevalence as a result of an increased focus on mental health disorders. To overcome this bias, we decided to run a second set of analysis taking into account overall healthcare spending and check if results from both analyses are comparable.

\section{METHODS}

\section{Data series}

\section{Dependent variable}

Prevalences of mental health issues across OECD countries were collected from the IHME's GBD project database, ${ }^{19}$ where data are estimated from a combination of surveys, medical and epidemiological data, as well as metaregression models. Data from the GBD study 2017 were released in November 2018 and concern years 1990-2017. The GBD study 2017 defines prevalence as the proportion of people in a population who are a case of a disease, injury or sequela. All results in GBD refer to point prevalence.

Data were extracted for year 2017 for a combination of mental health disorders and the specific following issues: depressive disorders, anxiety disorders, schizophrenia, bipolar disorders, eating disorders, alcohol use disorders, ADHD, autism spectrum disorders and suicide (table 1). Note that suicide did not include non-fatal self-harm.

Prevalence data were age standardised, which allowed comparability across populations when their age profiles were different. Data were calculated in relation to the entire population. Extracted data did not necessitate any further transformation and was ready to be used.
Independent variables

Each country's level of human development was measured with HDI (range: 0 to 1 ). The HDI summarises life expectancy, a combination of adult literacy rate and school enrolment rate, and gross domestic product per capita at purchasing power parity. ${ }^{20}$

For each country, income inequality was measured using the Gini index (range: 0 to 1 ), which intends to represent a nation's income distribution. ${ }^{21}$ A Gini coefficient of 0 means that the country income is perfectly equally distributed. A Gini coefficient of 1 means that all the country's income is received by just one person.

Our third socioeconomic indicator was unemployment rate, which measures the rate of unemployment as a percentage of the labour force. ${ }^{22}$

Data for the three predictors were collected from the OECD database except for HDI, which was retrieved from the United Nations Development Programme database (table 1). Data were extracted for year 2016, except when unavailable, in which case data were extracted for the closest year previous to 2016 (year range for data collection: 2014 to 2016 ).

Source data for all 36 OECD countries is available at https:// data.mendeley.com/datasets/xcycfh96x5/1. There was no missing data. For each indicator (dependent and independent variables), atypical countries were defined as having a z-score greater than 3 or below -3 (table 1).

\section{Statistical analysis}

We ran multiple regression linear models where the prevalence of a mental issue across OECD countries is predicted by the HDI, Gini index and unemployment rate. Extreme 
outliers were defined as data points with Cook's distance $>1 .{ }^{23}$ Using this cut-off, we were not able to identify any outliers when running our linear models.

For each mental health issue, we then converted each of the socioeconomic indicators' $t$ statistic into their corresponding effect size (Pearson's $r_{\mathrm{HDI}}, \mathrm{r}_{\text {Gini }}, \mathrm{r}_{\text {unemploy }}$ ). We then computed $2 \times 2$ Pearson's correlation coefficients between those three variables $\left(r_{\text {HDI-Gini, }}, r_{\text {HDI-unemploy }}, r_{\text {unemploy-Gini }}\right)$ to estimate their pairwise relationships across all mental health problems. Finally, to investigate the linear dependency between the three indicators' effect sizes, we ran principal component analysis and obtained explained variance for the first principal component.

An important caveat when collecting mental health data at the country level is that prevalence could reflect healthcare spending (which allows for more focus on mental health disorders) rather than giving a representative perspective on differences between countries. For our data, Pearson's $r$ between combined mental health disorders prevalence and healthcare spending as measured by price per capita at purchasing power parity (obtained from the OECD database $\left.^{24}\right)$ was of $0.58(\mathrm{p}<0.001)$. To check that our results were not impacted by overall healthcare expenditures, we decided to regress out the influence of healthcare spending on the prevalence of each mental health issue and to rerun our analysis using the residuals as dependent variables. Finally, to check that our results were not too influenced by outliers, we also ran our analysis using robust regression methods.

To run these analyses, we used R V.3.6.1.

\section{Patient and public involvement}

No patients were involved in this study.

\section{RESULTS}

Multiple linear regression models performed on the prevalence of a combination of mental health disorders revealed that the effect of development $\left(\mathrm{r}_{\mathrm{HDI}}\right)$, inequalities $\left(\mathrm{r}_{\mathrm{Gini}}\right)$ and unemployment $\left(\mathrm{r}_{\text {unemploy }}\right.$ ) was large ( $\mathrm{r}$ range: 0.51 to $0.76)$. However, they demonstrated great variation when measured among different mental health issues ( $\mathrm{r}$ range: -0.34 to 0.74 ; table 2 and online supplementary table 1 ), the most prominent being no positive effect on suicide and alcohol use disorders and a larger effect on other mental disorders. Regarding the latter, development had a strong effect $(r>0.65)$ on the prevalence of each disorder apart from bipolar disorders and ADHD $(r<0.43)$; income inequalities had at least a moderate effect $(r>0.40)$ on the prevalence of each disorder apart from bipolar disorders and ADHD $(r<0.30)$ and unemployment had a moderate effect on depressive and eating disorders $(r>0.42)$ and only a small effect on autism spectrum disorders and schizophrenia $(\mathrm{r}<0.18)($ table 2$)$.

Across mental issues, the socioeconomic indicators' effect sizes were strongly related to each other (Pearson's $\left.\mathrm{r}_{\text {HDI-Gini }}=0.93, \mathrm{r}_{\text {HDI-unemploy }}=0.81, \mathrm{r}_{\text {unemploy-Gini }}=0.84\right)$. Principal component analysis demonstrated that the first principal component of the three variables $\left(\mathrm{r}_{\mathrm{HDI}}, \mathrm{r}_{\text {Gini }}, \mathrm{r}_{\text {unemploy }}\right)$ explained $91.5 \%$ of the variance $(\mathrm{p}=0$, permutation test with 1000 repetitions).

Finally, note that rerunning our analysis after controlling for overall healthcare spending across countries and using robust method to control for outliers clearly reproduced this pattern of results (see online supplementary results, online supplementary tables 2 and 3 ).

\section{DISCUSSION}

This study aimed at clarifying the relationship between mental health and three socioeconomic factors: human development, income inequalities and unemployment. We first demonstrated that, among OECD countries, the strength of the relationship between the prevalence of mental health issues with development, inequalities and unemployment was large for a combination of disorders. This confirms the abundant literature showing a positive association between mental issues with inequalities ${ }^{9}$ and unemployment ${ }^{2526}$ for a whole range of mental disorders. More generally, the social science literature is unequivocal as per the association between a country's socioeconomic status and health across the life span. Indeed, other studies have demonstrated a strong impact of socioecological measures of wealth (eg, salary, pension), income inequalities, education and employment on overall health outcomes such as life expectancy, healthy life expectancy and adolescent health. ${ }^{27-31}$ Taking this a step further, our

Table 2 Effects of human development, income inequalities and unemployment on the prevalence of 10 mental health issues across OECD countries $(n=36)$

\begin{tabular}{lllllllllll}
\hline Pearson's $r$ & Combined & ASD & ADHD & DEP & SCZ & ANX & ED & ETOH & SUICIDE & BD \\
\hline$r_{\text {HDI }}$ & 0.76 & 0.74 & 0.21 & 0.68 & 0.72 & 0.65 & 0.74 & -0.27 & -0.07 & 0.43 \\
$r_{\text {Gini }}$ & 0.59 & 0.46 & 0.30 & 0.59 & 0.49 & 0.40 & 0.45 & -0.10 & -0.07 & 0.14 \\
$r_{\text {unemploy }}$ & 0.51 & 0.15 & 0.27 & 0.42 & 0.18 & 0.29 & 0.45 & -0.18 & -0.34 & 0.30 \\
\hline
\end{tabular}

Combined combination of autism spectrum disorders, attention-deficit hyperactivity disorders, conduct disorders, idiopathic developmental intellectual disability, depressive disorders, schizophrenia, anxiety disorders, eating disorders and bipolar disorders.

ADHD, attention-deficit hyperactivity disorders; ANX, anxiety disorders; ASD, autism spectrum disorders; BD, bipolar disorders; DEP, depressive disorders; ED, eating disorders; ETOH, alcohol use disorders; HDI, Human Development Index; OECD, Organization for Economic Cooperation and Development; SCZ, schizophrenia; SUICIDE, suicide rates. 
study adds one more argument for the implementation of public health policies expected to counter the devastating effect of inequalities and unemployment. ${ }^{10} 3233$

Aside from the effect of inequalities and unemployment on mental health, that of human development is less straightforward. On the one hand, research has shown that development was accompanied with better mental health. ${ }^{34}$ Human development clearly promotes health and well-being, for instance by reducing mortality due to infectious diseases thanks to vaccination programmes and antibiotics use and by encouraging education, innovations, freedom and opportunities. On the other hand, others have demonstrated an opposite relationship between mental health and human development, with mental disorders prevalence paradoxically increasing with the level of human development. ${ }^{17}$ The relationship between human development and mental health found in the current study was clearly of that kind, and this relationship was not related to overall healthcare spending. Some have interpreted this deleterious effect of development on mental health as a potential reflection of the mutation of social values towards less social integration and regulation in modern societies. ${ }^{35} 36$ In fact, the relationship between human development and mental health disorders prevalence may follow a U-shape curve, with a negative relationship (less mental disorders when development increases) for developing countries and a positive relationship (more mental disorders when development increases) for developed countries. Further studies should continue to investigate this association at a more fine-grained level, using for instance multilevel models, to better decipher the effect of human development on mental health in developing and developed countries.

In the current study, we were also interested in whether the association between mental health with human development, income inequalities and unemployment varies across mental issues and whether the three socioeconomic factors' effects on mental health are related to each other. As a second important result of our study, we demonstrated that the association between mental issues and the three socioeconomic factors was in fact relative to each mental health issue. Non-addictive mental health disorders tested in this study were clearly associated to these social factors, though to various degrees. Hypotheses on how each of those mental issues specifically relies to development, inequalities and unemployment are beyond the scope of this study and are open to further empirical testing. In contrast, development, inequalities and unemployment did not negatively impact suicide and alcohol use disorders. This seems to contradict withincountry studies that have demonstrated that inequalities and unemployment both affect suicide and alcohol use disorders prevalence. ${ }^{37-41}$ In fact, both issues are also thought to be strongly influenced by other sociocultural factors that vary independently from development, inequalities and unemployment. For instance, long-term unemployment ${ }^{42}$ or work stress ${ }^{43}$ have been associated to suicide, while religion, ${ }^{44}{ }^{45}$ connectedness and neighbourhood conditions ${ }^{46}$ are known protective factors against extreme behaviours. Overall, those additional factors, untested in this study, may have masked the effect of development, inequalities and unemployment on suicide and alcohol use.

A third important finding of our study is that the socioeconomic factors' effects on mental health are strongly related to each other. This suggests that they share an underlying common pathway. As such, they could pertain to a so-called social structure that would influence and restrict the choices and opportunities available to people ${ }^{47}$ and tend to bias an overall society towards better, or worse, mental health. In modern societies, development, inequalities and unemployment can all be viewed as indicators of key cultural values and norms important for social inclusion and cohesion. Such values and norms participate to some of the core features of capitalist systems: accumulation, competition and labour wages. That is, a high level of development sets priorities for people to reach a high threshold of desired outcomes in terms of education, health or financial wealth. ${ }^{48}$ Likewise, greater income inequalities can shape attitudes towards reaching a higher social position compared with others. ${ }^{49}$ Finally, the value of an employment position in this context is both material (it gives a source of income) and sociocultural (not having a job is typically perceived as being a failure in the society). Overall, these social factors' unifying feature may be their underlying pressure for success, which in turn could explain their negative impact on mental health.

\section{Limitations of this study}

First, because our research questions were directly related to the association of national-level mental health prevalence and socioeconomic indicators, we considered the ecological design the most appropriate for our study. ${ }^{8}$ However, the observational nature of our analysis implies that other uncontrolled sociocultural factors might have influenced the prevalence of mental issues in individual countries. We obviously need to be careful about any overinterpretation of our results as demonstrating causality while our models can only be predictive.

A second potential limitation of this study is the so-called ecological fallacy, that is, making inferences on individual risk from analysis made on aggregate data. ${ }^{50}$ Based on this study results, one cannot draw conclusions about the specific nature of individuals (eg, their socioeconomic status) who suffer from mental health issues. To solve this question, one would need to design a multilevel study where socioeconomic status at the individual level and at the country level would be entered as twolevel predictors.

Third, it is likely that the effect of development, inequalities and unemployment is different across non-OECD countries and especially low-income and middle-income countries. For instance, and as mentioned above, human development would have more of a beneficial effect on 
mental health in such developing countries. ${ }^{34}$ That said, as most of the European and North American populations were included in the current study, our results are probably generalisable to western countries.

\section{Conclusion}

Despite those limitations, these results implore a reanalysis of the socioeconomic determinants of mental health where: (1) the heterogeneity of mental health issues would be taken into account and (2) each socioeconomic indicator's effect would be analysed and interpreted in conjunction with the others.

Contributors All authors were involved in drafting the article or revising it critically for important intellectual content and have read and approved the final version of the manuscript. GB and NF designed the study. GB gathered the data. GB and NF analysed the data and wrote the paper.

Funding The authors have not declared a specific grant for this research from any funding agency in the public, commercial or not-for-profit sectors.

Competing interests None declared.

Patient consent for publication Not required.

Provenance and peer review Not commissioned; externally peer reviewed.

Data availability statement Data are available in a public, open-access repository.

Open access This is an open access article distributed in accordance with the Creative Commons Attribution Non Commercial (CC BY-NC 4.0) license, which permits others to distribute, remix, adapt, build upon this work non-commercially, and license their derivative works on different terms, provided the original work is properly cited, appropriate credit is given, any changes made indicated, and the use is non-commercial. See: http://creativecommons.org/licenses/by-nc/4.0/.

ORCID iD

Guillaume Barbalat http://orcid.org/0000-0002-8212-8053

\section{REFERENCES}

1 Silberberg D, Anand NP, Michels K, et al. Brain and other nervous system disorders across the lifespan - global challenges and opportunities. Nature 2015;527:S151-4.

2 World Health Organization. Suicide in the world: global health estimates. World Health Organization, 2019.

3 Schomerus G, Schwahn C, Holzinger A, et al. Evolution of public attitudes about mental illness: a systematic review and metaanalysis. Acta Psychiatr Scand 2012;125:440-52.

4 Kobau R, Seligman MEP, Peterson C, et al. Mental health promotion in public health: perspectives and strategies from positive psychology. Am J Public Health 2011;101:e1-9.

5 Bourgois P, Holmes SM, Sue K, et al. Structural vulnerability: operationalizing the concept to address health disparities in clinical care. Acad Med 2017;92:299.

6 Metzl JM, Hansen H. Structural competency and psychiatry. JAMA Psychiatry 2018;75:115-6.

7 Metzl JM, Petty J, Olowojoba OV. Using a structural competency framework to teach structural racism in pre-health education. Soc Sci Med 2018;199:189-201.

8 Wilkinson RG, Pickett KE. Income inequality and social dysfunction. Annu Rev Sociol 2009;35:493-511.

9 Ribeiro WS, Bauer A, Andrade MCR, et al. Income inequality and mental illness-related morbidity and resilience: a systematic review and meta-analysis. Lancet Psychiatry 2017;4:554-62.

10 Patel V, Burns JK, Dhingra M, et al. Income inequality and depression: a systematic review and meta-analysis of the association and a scoping review of mechanisms. World Psychiatry 2018;17:76-89.

11 Stuckler D, Basu S, Suhrcke M, et al. The public health effect of economic crises and alternative policy responses in Europe: an empirical analysis. Lancet 2009;374:315-23.

12 American Psychiatric Association. Diagnostic and statistical manual of mental disorders (DSM-5®). American Psychiatric Pub, 2013.
13 World Health Organization. The ICD-10 classification of mental and behavioural disorders: clinical descriptions and diagnostic guidelines. Geneva: World Health Organization, 1992.

14 Fried El. Problematic assumptions have slowed down depression research: why symptoms, not syndromes are the way forward. Front Psychol 2015;6:309.

15 Ranis G, Stewart F, Samman E. Human development: beyond the human development index. Journal of Human Development 2006; 7:323-58.

16 Joop TV, De Jong M. Public mental health, traumatic stress and human rights violations in low-income countries. In: Trauma, war, and violence: public mental health in socio-cultural context. Springer, 2002: 1-91

17 Cifuentes M, Sembajwe G, Tak S, et al. The association of major depressive episodes with income inequality and the human development index. Soc Sci Med 2008;67:529-39.

18 Whiteford H, Ferrari A, Degenhardt L. Global burden of disease studies: implications for mental and substance use disorders. Health Aff 2016;35:1114-20.

19 Global Burden of Disease Collaborative Network. Global burden of disease study 2017 (GBD2017) incidence, prevalence, and years lived with disability 1990-2017. Seattle, UnitedStates: Institute for Health Metrics and Evaluation (IHME), 2018. https://www.google.com/ search?q=Global+Burden+of+Disease+Collaborative+Network.+ Global+Burden+of+Disease+Study+2017+(GBD+2017)+Incidence\% 2C+Prevalence\%2C+and+Years+Lived+with+Disability+1990-2017.+ Seattle\%2C+United+States\%3A+Institute+for+Health+Metrics+and+ Evaluation+(IHME)\%2C+2018.\&rlz=1C1CHBD_enNZ738NZ739\& oq=Global+Burden+of+Disease+Collaborative+Network.+Global+ Burden+of+Disease+Study+2017+(GBD+2017)+Incidence\%2C+ Prevalence\%2C+and+Years+Lived+with+Disability+1990-2017.+ Seattle\%2C+United+States\%3A+Institute+for+Health+Metrics+ and+Evaluation+(IHME)\%2C+2018.\&aqs=chrome.69i57.260j0j4\& sourceid=chrome\&ie=UTF-8

20 United Nations Development Programme. Human development index. United Nations Human Developement Rep, 2019. http://hdr. undp.org/en/indicators/137506\#

21 The OECD. Income inequality. OECD data. Available: http://data. oecd.org/inequality/income-inequality.htm

22 The OECD. Unemployment rate. OECD data. Available: http://data oecd.org/unemp/unemployment-rate.htm

23 Cook RD. Detection of influential observation in linear regression. Technometrics 1977;19:15-18.

24 The OECD. Health spending. OECD data. Available: http://data.oecd. org/healthres/health-spending.htm [Accessed 21 Sep 2019].

25 Paul KI, Moser K. Unemployment impairs mental health: metaanalyses. J Vocat Behav 2009;74:264-82.

26 Artazcoz L, Benach J, Borrell C, et al. Unemployment and mental health: understanding the interactions among gender, family roles, and social class. Am J Public Health 2004;94:82-8.

$27 \mathrm{Kim} \mathrm{JI,} \mathrm{Kim} \mathrm{G.} \mathrm{Effects} \mathrm{on} \mathrm{inequality} \mathrm{in} \mathrm{life} \mathrm{expectancy} \mathrm{from} \mathrm{a} \mathrm{social}$ ecology perspective. BMC Public Health 2018;18:243.

28 Kim JI, Kim G. Socio-ecological perspective of older age life expectancy: income, gender inequality, and financial crisis in Europe. Global Health 2017;13:58.

$29 \mathrm{Kim} \mathrm{JI,} \mathrm{Kim} \mathrm{G.} \mathrm{Relationship} \mathrm{between} \mathrm{the} \mathrm{remaining} \mathrm{years} \mathrm{of} \mathrm{healthy}$ life expectancy in older age and national income level, educational attainment, and improved water quality. Int J Aging Hum Dev 2016;83:402-17.

$30 \mathrm{Kim}$ JI, Kim G. Labor force participation and secondary education of gender inequality index (GII) associated with healthy life expectancy (HLE) at birth. Int J Equity Health 2014;13:106.

31 Elgar FJ, Pförtner T-K, Moor I, et al. Socioeconomic inequalities in adolescent health 2002-2010: a time-series analysis of 34 countries participating in the health behaviour in school-aged children study. Lancet 2015;385:2088-95.

32 Pickett KE, Wilkinson RG. Immorality of inaction on inequality. BMJ 2017;356:j556.

33 Friedman EA, Gostin LO, Kavanagh MM, et al. Putting health equity at heart of universal coverage-the need for national programmes of action. BMJ 2019;367:I5901.

34 Lund C, Breen A, Flisher AJ, et al. Poverty and common mental disorders in low and middle income countries: a systematic review. Soc Sci Med 2010;71:517-28.

35 Böhnke P. Poverty and social integration in the enlarged Europe. WZB discussion paper, 2007.

36 Lester BY. Learnings from Durkheim and beyond: the economy and suicide. Suicide Life Threat Behav 2001;31:15-31.

37 Elgar FJ, Roberts C, Parry-Langdon N, et al. Income inequality and alcohol use: a multilevel analysis of drinking and drunkenness in adolescents in 34 countries. Eur J Public Health 2005;15:245-50. 
38 Lorant $\mathrm{V}$, Kunst AE, Huisman M, et al. Socio-economic inequalities in suicide: a European comparative study. Br J Psychiatry 2005;187:49-54.

39 Janlert U, Hammarström A. Alcohol consumption among unemployed youths: results from a prospective study. $\mathrm{Br} J$ Addict 1992;87:703-14.

40 Kposowa AJ. Unemployment and suicide: a cohort analysis of social factors predicting suicide in the US national longitudinal mortality study. Psychol Med 2001;31:127-38.

41 Reeves A, McKee M, Stuckler D. Economic suicides in the great recession in Europe and North America. Br J Psychiatry 2014;205:246-7.

42 Milner A, Page A, LaMontagne AD. Duration of unemployment and suicide in Australia over the period 1985-2006: an ecological investigation by sex and age during rising versus declining national unemployment rates. J Epidemiol Community Health 2013;67:237-44.

43 Boxer PA, Burnett C, Swanson N. Suicide and occupation: a review of the literature. J Occup Environ Med 1995;37:442-52.
44 Kleiman EM, Liu RT. Prospective prediction of suicide in a nationally representative sample: religious service attendance as a protective factor. Br J Psychiatry 2014;204:262-6.

45 Hodge DR, Cardenas P, Montoya H. Substance use: spirituality and religious participation as protective factors among rural youths. Soc Work Res 2001;25:153-61.

46 Oman RF, Vesely SK, Aspy CB, et al. A longitudinal study of youth assets, neighborhood conditions, and youth sexual behaviors. $J$ Adolesc Health 2013;52:779-85.

47 Barker C. The Sage dictionary of cultural studies. Sage, 2004.

48 James O. Affluenza-a contagious middle class virus causing depression, anxiety, addiction and ennui. London: Random House, 2007.

49 Pickett K, Wilkinson R. The spirit level: why equality is better for everyone. Penguin UK, 2010.

50 Piantadosi S, Byar DP, Green SB. The ecological fallacy. Am J Epidemiol 1988;127:893-904. 